\title{
Stay Slim or Get Fat?: An Examination of the "Jolly Fat" Effect in Chinese Older Adults
}

This article was published in the following Dove Press journal:

Risk Management and Healthcare Policy

\author{
Xiaojun Liu' \\ Shuoni Chen (iD) ${ }^{2}$ \\ Anran $\operatorname{Tan}^{2}$ \\ Jiayi Zhou (D) ${ }^{2}$ \\ Wenbin Liu'
}

'Department of Health Management, School of Public Health, Fujian Medical University, Fuzhou, Fujian, 350I22, People's Republic of China; ${ }^{2}$ Department of Global Health, Wuhan University, Wuhan, Hubei, 430072, People's Republic of China
Correspondence: Wenbin Liu Department of Health Management, School of Public Health, Fujian Medical University, Room 108 in the Building for School of Public Health, No. I Xuefubei Road, Minhou District, Fuzhou, 350122, People's Republic of China

$\mathrm{Tel} / \mathrm{Fax}+86-59 \mathrm{I}-2286-2572$

Email wenbinliu I26@I26.com
Purpose: The association between body mass index (BMI) and health-related quality of life (HRQOL) has not been verified neither in China nor in any other Asian country. This study aimed to examine the association between BMI and HRQOL in the Chinese older adults population.

Methods: A total of 5018 older adults from the China's Health-Related Quality of Life Survey for Older Adults 2018 was included in this study. The HRQOL was measured by the Chinese version of the World Health Organization Quality of Life Instrument-Older Adults Module (WHOQOL-OLD). Multiple linear regression analysis was used to explore the associations between BMI and HRQOL among the older adults in rural, urban, and total samples.

Results: After adjusting all the confounders, compared with normal weight group, underweight was negatively correlated with the total scores of HRQOL among the older adults in $\operatorname{rural}(\mathrm{B}=-2.310, \mathrm{p}<0.01)$, urban $(\mathrm{B}=-1.019, \mathrm{p}<0.001)$, and total samples $(\mathrm{B}=-2.351, \mathrm{p}<$ $0.001)$, whereas overweight was positively associated with the total scores of HRQOL among the older adults in rural samples $(B=0.888, p<0.05)$. The results showed that obesity was not associated with the total scores of HRQOL among the older adults in rural $(B=-1.214, p>0.05)$, urban $(B=-0.074, p>0.05)$, and total samples $(B=-1.461, p>0.05)$.

Conclusion: This study suggests that obese Chinese older adults did not show a better quality of life than those of normal weight. But this result does not deny the "jolly fat" hypothesis entirely, as the overweight older adults from rural areas showed better HRQOL. Moreover, underweight older people show a poorer HRQOL. The relationship between BMI and HRQOL in the older adults needs to be differentiated according to different characteristics of the population.

Keywords: body mass index, BMI, health-related quality of life, HRQOL, "jolly fat" hypothesis, Chinese older adults

\section{Introduction}

As the largest developing country, China now has the largest older adults population in the world. Experiencing the unprecedently rapid pace of population aging, by the end of 2018, China already had 249 million (17.9\%) people aged 60 and above, and is expected to enter the "super-aged" society $(20 \%)$ by $2035 .{ }^{1}$ The degradation of physiological functions will greatly impair the physical and mental health, as well as social adaptation of older adults, influencing the health-related quality of life (HRQOL) of the aging population. ${ }^{2-4}$

In order to actively respond to challenges brought by the population ageing and to improve the HRQOL for older adults, the World Health Organization (WHO) 
proposed the healthy aging strategy in $1980 \mathrm{~s}^{5}$ Accordingly, China launched the "Healthy China" strategy, which proposed to promote the health service system for older adults. ${ }^{6}$ However, difficulties occurred from the process of population ageing in China. To be more specific, for instance, obesity has become one of the health concerns in China. Substantial evidence revealed that China is one of the countries with extremely high rates of overweight and obesity citizens in the world, and the rates are on the rise. ${ }^{7,8} \mathrm{~A}$ study based on nine waves of China Health and Nutrition Survey (CHNS) data found that between 1991 and 2015, the prevalence of overweight and obesity among Chinese adults increased from $13.9 \%$ to $34.9 \%$ and $1.4 \%$ to $7.1 \%$, respectively. ${ }^{8}$

In general, researches have demonstrated the negative influence of either overweight or obesity on health outcomes, such as the increased risk of chronic noncommunicable diseases and the decrease of disability adjusted life year. ${ }^{9}$ However, there have been some studies suggesting the different or even contrary conclusions on the relationship between body weight and health, particularly the positive associations between BMI and mental health. ${ }^{10-12}$ Studies have shown that higher BMI was significantly associated with better mental health condition and happenings, which was named as the "jolly fat" hypothesis. ${ }^{13-15}$ The hypothesis has been fully or partially supported by various cross-sectional studies and cohort studies from different countries. Specifically, BMI appeared to have differential effects on physical and mental health among different subgroups. For example, depression was negatively associated with BMI in older females. $^{16}$

However, unlike the "jolly fat" hypothesis, BMI was found to be positively associated with depression in other studies. ${ }^{17-19}$ In a US national study, researchers found that overweight was associated with an increased risk of depression in males, and in females, both overweight and obesity showed increased risk. ${ }^{18}$ One Canadian study also discovered the negative effect of overweight on depression in males, while there was no association in females. ${ }^{19}$ Besides, there were also studies showing no association between depression and obesity. ${ }^{20,21}$ Similar to "jolly fat" hypothesis, a Chinese proverb - laugh while grow fat - refers to a positive association between body weight and subjective well-being, while some Chinese studies concerning the proverb have also shown inconsistent outcomes. $^{22-25}$ In these studies, HRQOL, as the best indicator of subjective well-being, was measured via various methods. Yet the present study adopts the Chinese version of the world health organization quality of life instrument-older adults module (WHOQOL-OLD) to assess HRQOL. The good feasibility, reliability and validity of the Chinese version of WHOQOL-OLD have been verified. ${ }^{26}$

\section{Materials and Methods Material Sources}

The data of this study were from the 2018 China's Health-Related Quality of Life Survey for Older Adults (CHRQLS-OA 2018). The CHRQLS-OA 2018 was conducted by the Global Health Institute of Wuhan University, which aimed to collect data on the sociodemographic characteristics, social capital, healthrelated behaviors and lifestyles, health-related quality of life of older adults aged 60 years and over across the country. With the intention of ensuring a balanced distribution of the country's population, the survey was conducted between January and March of 2018. The survey was used a convenience sampling strategy to get more enrollments during the specific period of data collection time. ${ }^{27}$ Whilst the general database contains 5442 valid samples, the present study only included 5018 valid subjects in the final analysis. Because we excluded 524 samples $(7.79 \%)$ without information on height, weight, and/or HRQOL.

\section{Assessment of Health-Related Quality of Life}

The Chinese version of the world health organization quality of life instrument-older adults module (WHOQOLOLD) was employed to assess the status of participants' health-related quality of life conditions in the present study. The Chinese version of WHOQOL-OLD is a 5-point Likert scale that consists of 24 items divided into 6 domains (each of the domains has 4 items), namely "Sensory Abilities" (SAB), "Autonomy" (AUT), "Past, Present and Future Activities" (PPF), "Social Participation" (SOP), "Death and Dying" (DAD), and "Intimacy" (INT). The scores of each item range from 1 to 5 points, and the score of each domain ranges from a minimum of 4 to a maximum of 20 points, and the total score varies from 24 to 120 . A higher score indicates a better HRQOL. The good internal consistency and reliability of the Chinese version of WHOQOL-OLD has been confirmed. $^{26}$ 


\section{Assessment of Body Mass Index}

In the CHRQLS-OA 2018 questionnaire, body mass index (BMI) was calculated as the ratio of weight (kilogram, $\mathrm{kg}$ ) to the square of height (meter, $\mathrm{m}$ ). The participants were asked to report their height and weight. According to Chinese criteria, individuals' BMI were classified as underweight $\left(<18.50 \mathrm{~kg} / \mathrm{m}^{2}\right)$, normal $\left(18.50 \mathrm{~kg} / \mathrm{m}^{2}\right.$ to $\left.23.99 \mathrm{~kg} / \mathrm{m}^{2}\right)$, overweight $\left(24.00 \mathrm{~kg} / \mathrm{m}^{2}\right.$ to $\left.27.99 \mathrm{~kg} / \mathrm{m}^{2}\right)$, and obese $\left(\geq 28.00 \mathrm{~kg} / \mathrm{m}^{2}\right)$.

\section{Covariates}

In the present study, individual and familial sociodemographic characteristics of the subjects, including participants' sex, age, nationality, years of schooling, marital status, household per capita income (CNY), personal savings (CNY), self-rated health status, and registered permanent residence were considered as confounder factors. Age was classified into 6 groups: 60-64 years old; 65-69 years old; 70-74 years old; 75-79 years old; 80-84 years old, and 85 years old and above. Nationality includes Han and non-Han, and non-Han are considered ethnic minorities. Years of schooling was classified into 5 categories: no formal education ( 0 ); received $1-5$ years of education; received 6-8 years of education; received 9-11 years of education; received 12 years of education or more. Marital status was divided into two groups as "Single/widower/ divorced" and "Married/partner". Household per capita income was classified into 5 categories: $<15,000$ yuan, $15,000-30,000$ yuan, $30,000-45,000$ yuan, $45,000-60,000$ yuan, and $>60,000$ yuan. Personal savings was classified into 5 categories: $<10,000$ yuan, $10,000-30,000$ yuan, 30 ,000-50,000 yuan, 50,000-100,000 yuan, and $\geq 100,000$ yuan. Self-rated health status was based on individuals' subjective feelings, and the variable was divided into three groups, which were "Good", "Fair", and "Poor". Registered permanent residence includes two types: rural and urban.

\section{Statistics Analysis}

The Statistical Package for the Social Sciences (SPSS) version 23.0 for Windows (SPSS Inc., Chicago, IL, USA) was applied to conduct all statistical analyses. A twosided p-value of less than 5\% was considered to be statistically significant. Data analysis was performed in the following 3 steps: Firstly, the social-demographic variables of the participants were descriptively analyzed by total samples, rural and urban samples, and frequencies were reported. Secondly, one-way analysis of variance (ANOVA) was conducted to compare the differences of HRQOL in different BMI groups, and the post hoc tests were performed to explore specific differences in HRQOL among the older adults with different BMIs. Lastly, we employed the multiple linear regression analysis to examine the associations between the BMI and HRQOL among the older adults in rural, urban, and total samples. The multiple linear regression models adjusted for potential confounders. The results were reported as an unstandardized coefficient (B) obtained from the models.

\section{Ethical Statement}

The study was conducted according to the guidelines of the Declaration of Helsinki, and approved by the Institutional Review Board of School of Health Science and Faculty of Medical Sciences, Wuhan University (IRB number: 2019YF2050). The potential participants were fully informed of the contents and aims of this survey. Only those who were willing to voluntarily participate and signed the informed consent form were considered as our final respondents in the survey.

\section{Results}

\section{Demographic Characteristics of the Study Sample}

As Table 1 shows, a total of 5018 individuals composed of $2514(50.40 \%)$ women and $2474(49.60 \%)$ men were involved in the cross-sectional study, including 1979 (39.44\%) respondents living in urban areas and 2974 (59.27\%) respondents living in rural areas. Sample sizes within characteristics may not sum to 5018 due to missing values. There were $540(10.76 \%)$ respondents with a BMI of less than $18.5 \mathrm{~kg} / \mathrm{m}^{2}, 3151(62.79 \%)$ respondents with BMI normal, 1097 (21.86\%) respondents with a BMI between $24.00 \mathrm{~kg} / \mathrm{m}^{2}$ to $27.99 \mathrm{~kg} / \mathrm{m}^{2}$, and $230(4.58 \%)$ respondents with a BMI $\geq 28.00 \mathrm{~kg} / \mathrm{m}^{2}$. Of the urban older adults, participants with underweight, normal, overweight and obese were 166 (8.39\%), 1183 (59.78\%), 541 (27.34\%) and 89 (4.50\%), respectively. Of the rural older adults, participants with underweight, normal, overweight and obese were $364(12.24 \%), 1933$ (65.00\%), 541 $(18.19 \%)$ and 136 (4.57\%), respectively. Significant differences were revealed on the distribution of age, nationality, years of schooling, marital status, household per capita income (RMB), personal savings (RMB), health status, 
Table I Distributions of Selected Variables of the Participants Stratified by Registered Permanent Residence

\begin{tabular}{|c|c|c|c|c|c|}
\hline \multirow[t]{2}{*}{ Variables } & Total & Rural & Urban & \multirow[t]{2}{*}{$\chi^{2}$} & \multirow[t]{2}{*}{$P$ value } \\
\hline & $n=5018$ & $n=2974$ & $n=1979$ & & \\
\hline \multicolumn{6}{|l|}{ Sex } \\
\hline Male & 2474 & 1464 & 981 & 0.071 & 0.789 \\
\hline Female & 2514 & 1493 & 985 & & \\
\hline \multicolumn{6}{|l|}{ Age groups } \\
\hline $60-64$ & 1105 & 692 & 396 & 13.358 & 0.020 \\
\hline $65-69$ & 1165 & 703 & 444 & & \\
\hline $70-74$ & 1164 & 670 & 480 & & \\
\hline $75-79$ & 727 & 402 & 317 & & \\
\hline $80-84$ & 553 & 325 & 223 & & \\
\hline$\geq 85$ & 295 & 178 & 114 & & \\
\hline \multicolumn{6}{|l|}{ Nationality } \\
\hline Han & 4683 & 2819 & 1814 & 22.011 & $<0.001$ \\
\hline Ethnic minority & 245 & 109 & 130 & & \\
\hline \multicolumn{6}{|l|}{ Years of schooling } \\
\hline 0 & 1116 & 948 & 163 & 678.458 & $<0.001$ \\
\hline $\mathrm{I}-5$ & 1430 & 902 & 510 & & \\
\hline $6-8$ & 908 & 493 & 401 & & \\
\hline $9-11$ & 682 & 309 & 359 & & \\
\hline$\geq 12$ & 595 & 142 & 444 & & \\
\hline \multicolumn{6}{|l|}{ Marital status } \\
\hline Single/widower/divorced & 1800 & 1171 & 610 & 38.560 & $<0.001$ \\
\hline Married/partner & 3188 & 1787 & 1363 & & \\
\hline \multicolumn{6}{|l|}{$\begin{array}{l}\text { Household per capita income } \\
\text { (RMB) }\end{array}$} \\
\hline$<15,000$ & 1767 & 1422 & 329 & 1085.319 & $<0.001$ \\
\hline $15,000-30,000$ & 1222 & 877 & 339 & & \\
\hline $30,000-45,000$ & 942 & 410 & 516 & & \\
\hline $45,000-60,000$ & 550 & $|4|$ & 395 & & \\
\hline$>60,000$ & 469 & 86 & 379 & & \\
\hline \multicolumn{6}{|l|}{ Personal savings (RMB) } \\
\hline$<10,000$ & 1929 & 1574 & 337 & 1147.396 & $<0.001$ \\
\hline $10,000-30,000$ & 1017 & 682 & 323 & & \\
\hline $30,000-50,000$ & 632 & 355 & 269 & & \\
\hline $50,000-100,000$ & 708 & 221 & 479 & & \\
\hline$\geq 100,000$ & 688 & 124 & 548 & & \\
\hline \multicolumn{6}{|l|}{ Self-rated health status } \\
\hline Good & 1480 & 722 & 731 & 185.413 & $<0.001$ \\
\hline Fair & 2526 & 1483 & 1017 & & \\
\hline Poor & 1009 & 768 & 229 & & \\
\hline \multicolumn{6}{|l|}{ BMI category } \\
\hline Underweight & 540 & 364 & 166 & 67.133 & $<0.001$ \\
\hline Normal weight & 3151 & 1933 & 1183 & & \\
\hline Overweight & 1097 & 541 & 541 & & \\
\hline Obese & 230 & 136 & 89 & & \\
\hline
\end{tabular}

Note: Sample sizes within characteristics may not sum to $n=5018$ due to missing values. 
Table 2 HRQOL Scores of the Participants Stratified by BMI (Data Presented as Mean \pm Standard Deviation)

\begin{tabular}{|c|c|c|c|c|c|c|c|}
\hline Domains & $\begin{array}{c}\text { Underweight } \\
\text { (g I) }\end{array}$ & $\begin{array}{c}\text { Normal } \\
\text { (g 2) }\end{array}$ & $\begin{array}{c}\text { Overweight } \\
\text { (g 3) }\end{array}$ & $\begin{array}{l}\text { Obese } \\
\left(\begin{array}{l}\text { ( 4) }\end{array}\right.\end{array}$ & $\boldsymbol{F}$ & $P$ value & $\begin{array}{c}\text { Multiple } \\
\text { Comparisons }\end{array}$ \\
\hline \multicolumn{8}{|l|}{ Total sample $(n=50 \mid 8)$} \\
\hline $\mathrm{SAB}$ & $12.48 \pm 3.62$ & $12.84 \pm 3.53$ & $13.55 \pm 3.52$ & $13.03 \pm 3.52$ & 14.725 & $<0.001$ & $g \mid<g 2, g$ g $4<3$ \\
\hline AUT & $13.43 \pm 3.45$ & $|3.50 \pm 3.3|$ & $|4.1| \pm 3.38$ & $14.04 \pm 3.16$ & 11.036 & $<0.001$ & $\mathrm{~g}$ I, g $2<\mathrm{g} 3, \mathrm{~g} 4$ \\
\hline PPF & $12.93 \pm 2.95$ & $12.99 \pm 2.98$ & $13.46 \pm 3.19$ & $13.32 \pm 3.17$ & 7.524 & $<0.001$ & g I, g $2<$ g 3 \\
\hline SOP & $12.83 \pm 2.96$ & $12.85 \pm 2.95$ & $13.33 \pm 3.00$ & $|3.20 \pm 3.1|$ & 7.886 & $<0.001$ & g I, g $2<$ g 3 \\
\hline DAD & $12.06 \pm 3.32$ & $12.46 \pm 3.50$ & $|2.16 \pm 3.4|$ & $11.96 \pm 3.50$ & 2.413 & 0.065 & - \\
\hline INT & $12.63 \pm 3.34$ & $12.97 \pm 3.47$ & $13.05 \pm 3.48$ & $13.25 \pm 3.23$ & 6.317 & $<0.001$ & $\mathrm{~g} \mid<\mathrm{g} 2, \mathrm{~g} 3, \mathrm{~g} 4$ \\
\hline Total & $76.88 \pm|3.5|$ & $77.10 \pm 13.19$ & $79.67 \pm 13.78$ & $78.79 \pm 12.46$ & 12.438 & $<0.001$ & $\mathrm{~g} \mid<\mathrm{g} 3, \mathrm{~g} 4$ \\
\hline \multicolumn{8}{|l|}{ Rural sample $(n=2974)$} \\
\hline$S A B$ & $12.07 \pm 3.60$ & $|2.2| \pm 3.5 \mid$ & $12.72 \pm 3.37$ & $12.88 \pm 3.66$ & 4.753 & 0.003 & $\mathrm{~g}$ I, g $2<\mathrm{g} 3, \mathrm{~g} 4$ \\
\hline AUT & $13.07 \pm 3.17$ & $13.33 \pm 3.39$ & $13.5 \mid \pm 3.13$ & $12.86 \pm 3.24$ & 4.283 & 0.005 & g $4<\mathrm{g} 2, \mathrm{~g} 3$ \\
\hline PPF & $12.46 \pm 2.97$ & $12.59 \pm 2.65$ & $12.63 \pm 3.13$ & $|2.7| \pm 3.3 \mid$ & 0.751 & 0.522 & - \\
\hline SOP & $|2.28 \pm 2.9|$ & $|2.60 \pm 2.7|$ & $|2.57 \pm 3.0|$ & $12.85 \pm 3.22$ & 3.293 & 0.020 & $g \mid<g ~ 3, g ~ 4$ \\
\hline DAD & $11.76 \pm 3.27$ & $12.23 \pm 3.27$ & $|1.74 \pm 3.4|$ & $11.85 \pm 3.64$ & 2.166 & 0.090 & - \\
\hline INT & $12.30 \pm 3.35$ & $12.81 \pm 3.17$ & $12.98 \pm 3.18$ & $12.57 \pm 3.66$ & 3.967 & 0.008 & $\mathrm{~g} I<\mathrm{g} 2, \mathrm{~g} 3$ \\
\hline Total & $73.86 \pm 13.67$ & $75.37 \pm 11.90$ & $76.76 \pm 12.47$ & $75.57 \pm \mid 4.11$ & 4.331 & 0.005 & $g \mid<g 3, g 4$ \\
\hline \multicolumn{8}{|l|}{$\begin{array}{l}\text { Urban sample } \\
(n=1979)\end{array}$} \\
\hline$S A B$ & $13.17 \pm 3.62$ & $13.89 \pm 3.30$ & $14.40 \pm 3.46$ & $13.33 \pm 3.32$ & 7.245 & $<0.001$ & $g \mid<g 2, g 3$ \\
\hline AUT & $14.23 \pm 3.93$ & $14.55 \pm 3.15$ & $14.89 \pm 3.16$ & $14.84 \pm 3.09$ & 2.327 & 0.073 & - \\
\hline PPF & $13.69 \pm 3.40$ & $13.85 \pm 2.80$ & $14.30 \pm 3.05$ & $14.28 \pm 2.78$ & 3.745 & 0.011 & $g \mid<g 3$ \\
\hline SOP & $13.27 \pm 3.38$ & $13.77 \pm 2.78$ & $|4.1| \pm 2.8 \mid$ & $13.79 \pm 2.93$ & 4.017 & 0.007 & $\mathrm{~g} I<\mathrm{g} 2, \mathrm{~g} 3$ \\
\hline DAD & $12.97 \pm 3.86$ & $12.56 \pm 3.33$ & $12.55 \pm 3.37$ & $12.15 \pm 3.36$ & 1.241 & 0.293 & - \\
\hline INT & $13.30 \pm 4.03$ & $13.18 \pm 3.26$ & $13.52 \pm 3.20$ & $13.75 \pm 3.33$ & 1.876 & 0.132 & - \\
\hline Total & $80.63 \pm 14.93$ & $81.80 \pm 11.79$ & $83.77 \pm 12.20$ & $82.13 \pm 12.04$ & 4.285 & 0.005 & $g \mid<g 2<g 3$ \\
\hline
\end{tabular}

Abbreviations: SAB, sensory abilities; AUT, autonomy; PPF, past, present and future activities; SOP, social participation; DAD, death and dying; INT, intimacy.

BMI category among the participants with different living area (all p-values less than 0.05 ).

\section{Scores of the WHOQOL-OLD Scale}

HRQOL was measured from six domains, including SAB, AUT, PPF, SOP, DAD, and INT. In total sample, the scores of overweight group and obese group are statistically higher than underweight. The mean values of HRQOL scores were significantly different in all domains and the overall level among individuals with different groups of BMI ( $p<0.001)$, except for DAD. Moreover, the lowest scores of SAB, AUT, PPF, SOP, INT were observed in underweight group, while the higher scores were found in overweight group and/or obese group. In urban samples, the scores of overweight group and obese group are statistically higher than underweight group. The mean values of HRQOL scores were significantly different in all domains and the total level among individuals with different groups of BMI $(p<0.05)$, except for AUT, DAD, and
INT. The lowest scores of SAB, PPF, SOP were observed in underweight group, while the higher scores were found in overweight group and obese group. In rural samples, the scores of overweight group and obese group are statistically higher than underweight group. The mean values of HRQOL scores were significantly different in all domains and the total level among individuals with different groups of BMI $(p<0.05)$, except for PPF and DAD. The lowest scores of SAB, SOP, INT were observed in underweight group, while the higher scores were found in overweight and/or obese group. Especially, the lowest score of AUT was observed in obese group, while the highest score was found in overweight group. The results are shown in Table 2 .

\section{Association Between BMI HRQOL}

As demonstrated in Table 3, the results of the linear regression analysis were consistent in model 1 and model 2. The final parsimonious model (model 2) revealed that, 
Table 3 Linear Regression Models Testing the Association Between BMI and HRQOL (Reference= Normal Weight)

\begin{tabular}{|c|c|c|c|c|c|c|c|}
\hline \multirow[t]{2}{*}{ Models } & SAB & AUT & PPF & SOP & DAD & INT & \multirow{3}{*}{$\begin{array}{l}\text { Total } \\
\text { Score }\end{array}$} \\
\hline & \multicolumn{6}{|c|}{ Unstandardized Coefficients $\beta$} & \\
\hline \multicolumn{7}{|l|}{$\begin{array}{l}\text { Total sample } \\
(n=50 \mid 8)\end{array}$} & \\
\hline \multicolumn{8}{|l|}{ Model I } \\
\hline Underweight & $-0.310 *$ & $-0.292 *$ & -0.247 & $-0.312 *$ & $-0.619 * * *$ & $-0.567 * * *$ & $-2.347 * * *$ \\
\hline Overweight & 0.182 & 0.108 & 0.139 & 0.199 & 0.851 & $0.528 * *$ & 2.007 \\
\hline Obese & -0.168 & -0.038 & -0.174 & -0.084 & $-0.875 * *$ & -0.047 & -1.297 \\
\hline \multicolumn{8}{|l|}{ Model 2} \\
\hline Underweight & $-0.301 *$ & $-0.278 *$ & -0.253 & $-0.303 *$ & $-0.619 * * *$ & $-0.593 * * *$ & $-2.351 * * *$ \\
\hline Overweight & 0.170 & 0.076 & 0.152 & 0.178 & 0.851 & $0.570 * *$ & 2.008 \\
\hline Obese & -0.160 & -0.014 & -0.159 & -0.075 & $-0.875 * *$ & -0.034 & -1.214 \\
\hline \multicolumn{8}{|l|}{$\begin{array}{l}\text { Rural sample } \\
(\mathrm{n}=2974)\end{array}$} \\
\hline \multicolumn{8}{|l|}{ Model I } \\
\hline Underweight & $-0.358 *$ & -0.246 & -0.123 & $-0.438 * *$ & $-0.559 * *$ & $-0.509 * *$ & $-2.274 * *$ \\
\hline Overweight & 0.351 & 0.166 & 0.265 & $0.502 * *$ & $0.962 * * *$ & $0.620 * *$ & $0.866 *$ \\
\hline Obese & 0.239 & -0.121 & -0.112 & 0.016 & -0.664 & 0.274 & -0.125 \\
\hline \multicolumn{8}{|l|}{ Model 2} \\
\hline Underweight & $-0.363 *$ & -0.235 & -0.137 & $-0.440 * *$ & $-0.57 \mid * *$ & $-0.539 * *$ & $-2.310 * *$ \\
\hline Overweight & 0.336 & 0.143 & 0.279 & $0.492 * *$ & $0.901 * * *$ & $0.664 * *$ & $0.888 *$ \\
\hline Obese & 0.246 & -0.141 & -0.118 & 0.038 & -0.614 & 0.257 & -0.074 \\
\hline \multicolumn{8}{|l|}{$\begin{array}{l}\text { Urban sample } \\
(n=1979)\end{array}$} \\
\hline \multicolumn{8}{|l|}{ Model I } \\
\hline Underweight & -0.090 & -0.051 & -0.166 & $-0.178 *$ & $-0.434 *$ & $-0.518 *$ & $-1.083 * * *$ \\
\hline Overweight & 0.122 & 0.239 & 0.200 & 0.448 & -0.546 & -0.337 & 0.125 \\
\hline Obese & -0.549 & 0.085 & 0.028 & 0.123 & $-1.029 *$ & -0.159 & -1.501 \\
\hline \multicolumn{8}{|l|}{ Model 2} \\
\hline Underweight & -0.022 & -0.040 & -0.148 & $-0.143 *$ & -0.471 & -0.523 & $-1.019 * * *$ \\
\hline Overweight & 0.168 & 0.284 & 0.218 & 0.402 & -0.582 & -0.339 & 0.228 \\
\hline Obese & -0.498 & 0.123 & 0.021 & 0.115 & $-1.042 *$ & -0.134 & $-1.46 \mid$ \\
\hline
\end{tabular}

Notes: ${ }^{*} p$-value $<0.05 ; *$-value $<0.01 ; * * *$-value $<0.001$. Model I adjusted for all the predictors (sex, age, nationality, BMI) using stepwise. Model 2 is the final parsimonious model, adjusted for all the potential predictors (sex, age, nationality, BMI) using enter method.

compared with normal weight group, in total sample, underweight group was negatively correlated with the scores of SAB $(B=-0.310, p<0.05)$, AUT $(B=-0.292$, $\mathrm{p}<0.05)$, SOP $(\mathrm{B}=-0.312, \mathrm{p}<0.05)$, DAD $(\mathrm{B}=-0.619$, $\mathrm{p}<0.001)$, INT $(\mathrm{B}=-0.567, \mathrm{p}<0.001)$ and total score $(B=-2.347, p<0.001)$, obesity group was negatively correlated with the score of DAD $(B=-0.875, p<0.01)$, whereas overweight group was positively associated with the score of INT. In rural sample, underweight group was negatively correlated with the scores of $\mathrm{SAB}(\mathrm{B}=-0.363$, $\mathrm{p}<0.05)$, SOP $(\mathrm{B}=-0.440, \mathrm{p}<0.01), \mathrm{DAD}(\mathrm{B}=-0.571$, $\mathrm{p}<0.01)$, INT $(\mathrm{B}=-0.539, \mathrm{p}<0.01)$ and total score $(\mathrm{B}=$ $-2.310, \mathrm{p}<0.01)$, while overweight group was positively associated with the scores of SOP $(B=0.492, p<0.01)$, DAD $(B=0.901, p<0.001)$, INT $(B=0.664, p<0.01)$, and total score $(B=0.888, p<0.05)$. In urban sample, underweight group was negatively correlated with the scores of SOP $(B=-0.143, p<0.05)$ and total score $(B=$ $-1.019, \mathrm{p}<0.001)$, and obese group was negatively correlated with the score of DAD $(\mathrm{B}=-1.042, \mathrm{p}<0.05)$. 


\section{Discussion}

In this study, we tested the "jolly fat" hypothesis in the context of investigating the association between BMI and HRQOL among Chinese older adults. In general, older adults with a lower BMI had a worse HRQOL. However, in this study, overweight and obesity did not exhibit a significant positive association with HRQOL among the general older population or older urban residents, which was inconsistent with the "jolly fat" hypothesis and the Chinese proverb "laugh while grow fat". However, in rural areas, overweight was positively associated with a better HRQOL, while older adults with obesity showed a worse HRQOL as compared to those with normal BMI. Therefore, our study partly supported the "jolly fat" hypothesis and the Chinese proverb "laugh while grow fat" as for the older population in China. This phenomenon was most evident among the older adults residents living in rural communities.

Findings from a cross-sectional study of 44 to 56 aged Korean women indicated that the relationship between obesity and depressive symptoms supported the "jolly fat" hypothesis, and they believed that stress is an important potential mediator exerting effects on the relationship between obesity and depressive symptoms, as obese women were richer and thus less stressed. ${ }^{13}$ In the present study, this association was only found among overweight older adults in rural areas, while there was no evidence for others, such as obese older adults in rural areas, the overall population or older urban residents. The findings are similar to those of another large-scale cross-sectional study conducted in China, which revealed that overweight and obesity associated with a lower prevalence of depressive symptoms in the Chinese rural population. ${ }^{29}$ The fact that overweight older adults in rural areas had better performances in SOP, DAD, INT and overall HRQOL might be attributed to their richer social capitals, as compared with the underweight older adults or those older adults with normal weight from rural areas. ${ }^{21}$ Since the economy and society in rural areas in China were not as developed as in cities.

The association of HRQOL and underweight has been given much less attention compared to the association between overweight/obesity and HRQOL. The current study found the worse HRQOL among underweight older adults in both the full sample and in sub-samples stratified by registered permanent residence. Results from a largescale cross-sectional study conducted in rural China also suggested that underweight was associated with a higher prevalence of depressive symptoms in Chinese rural adults, which indicated that not only we should pay attention to overweight and/or obesity, but also underweight. ${ }^{29}$ Especially for the older adults, it was shown that the highest level of depressive symptoms was found among the underweight older adults. ${ }^{30}$ A British study also found that underweight people were more likely to develop depression, which indicated a higher risk of worse HRQOL. ${ }^{31}$ Several Chinese studies confirmed that underweight population had worse HRQOL, too. ${ }^{24,32,33}$

In this study, we observed inverse correlations between underweight and HRQOL among the general older population and older rural and urban residents. By further exploring the domains of HRQOL, we found that in general, underweight older adults showed a worse HRQOL in all dimensions except PPF. In rural areas, underweight older adults had a worse HRQOL in all dimensions except AUT and PPF, while for older urban residents, those with a lower BMI only demonstrated lower scores in SOP. In the general older population, overweight was associated with better scores in INT. As for overweight older adults in rural areas, their HRQOL were better in the dimensions of SOP, DAD, INT than those with normal BMI. Therefore, we suggest that the implementation of relevant health management for the elderly needs to pay attention to the BMI, to ensure that the elderly have a healthy diet and adequate intake of nutrients to prevent underweight.

These findings suggested that the association between BMI and HRQOL is by no means simple. Studies have shown contradictory results regarding the "jolly fat" hypothesis. ${ }^{34-36}$ The inconsistent findings could be caused by the heterogeneity in study design, sample size, sample demographic characteristics and cultural context. ${ }^{15,37}$ Therefore, further studies are needed to validate the association between BMI and HRQOL. In this research, the following potential imitations should be noted. First, the cross-sectional design does not guarantee the causal inference of BMI and HRQOL. Therefore, additional prospective researches are needed. Second, the measurement of BMI was based on self-reported height and weight, in which people were likely to overreport their height and underreport their weight, which would undermine the accuracy and validity. ${ }^{38}$ However, we believe the bias was quite small and thus acceptable, and studies had also proven the accuracy of self-reported BMI on evaluating the prevalence of overweight or obesity. ${ }^{39}$ Third, it was questionable to use BMI as the standard of identifying 
obesity. Romero-Corral found a limited accuracy in predicting obesity by BMI, especially for older adults and people with intermediate BMI. ${ }^{40}$

\section{Conclusion}

The results of this study did not fully support the "jolly fat" hypothesis among the Chinese older adults population. Our study did not show overweight and obesity were correlated positively with HRQOL among the general older population or older urban residents. However, in rural samples, overweight was positively associated with a better HRQOL, while obese older adults showed a worse HRQOL as compared to those with normal BMI. This study demonstrated that underweight older adults had poorer HRQOL, regardless of whether they came from urban or rural areas.

\section{Acknowledgments}

The data used in this study came from the China's HealthRelated Quality of Life Survey for Older Adults 2018, and this project was funded by Wuhan University "Double First-Class (World's First-Class University \&World's First-Class Disciplines)" development (Special fund \#C). The present study was also supported by Fujian Medical University's high-level talent research start-up project (Grant No. XRCZX2020020).

\section{Disclosure}

The authors report no conflicts of interest in this work.

\section{References}

1. United Nations. Department of economic and social affairs, population division [homepage on the Internet]. World Population Prospects 2019; 2019. Available from: https://population.un.org/wpp/Download/ Standard/Population. Accessed December 25, 2020.

2. Buhl R, van Schayck O, Aubier M, Ostinelli J, Jorgensen L, Haughney J. Impact of age, age at diagnosis and duration of asthma on the risk of exacerbations in the EuroSMART study. Eur Respir J. 2012;40:1.

3. Kumar A, Solanki RK, Nebhinani N. Depression in elderly: phenomenology, neurobiology and management of late onset depression. Indian J Psychiatry. 2018;60(5):30. doi:10.4103/ijsp.ijsp_120_17

4. Arbus C, Hergueta T, Duburcq A, et al. Adjustment disorder with anxiety in old age: comparing prevalence and clinical management in primary care and mental health care. Eur Psychiatry. 2014;29 (4):233-238. doi:10.1016/j.eurpsy.2013.04.002

5. Beard JR, Officer A, de Carvalho IA, et al. The world report on ageing and health: a policy framework for healthy ageing. Lancet. 2016;387 (10033):2145-2154. doi:10.1016/S0140-6736(15)00516-4

6. Tan XD, Zhang YN, Shao HY. Healthy China 2030, a breakthrough for improving health. Glob Health Promot. 2019;26(4):96-99. doi:10.1177/1757975917743533

7. Wang Y, Wang L, Qu W. New national data show alarming increase in obesity and noncommunicable chronic diseases in China. Eur J Clin Nutr. 2017;71(1):149-150. doi:10.1038/ejen.2016.171
8. Bai R, Wu W, Dong W, Liu J, Yang L, Lyu J. Forecasting the populations of overweight and obese Chinese adults. Diabetes Metab Syndr Obes. 2020;13:4849-4857. doi:10.2147/DMSO. S274110

9. Nardi E, Minami B. Chronic non-communicable diseases (NCDS) and body mass index (BMI) of beneficiaries and non-beneficiaries of private health plans in Brazil. Value Health. 2017;20(9):A910-A910.

10. Qian J, Li N, Ren X. Obesity and depressive symptoms among Chinese people aged 45 and over. Sci Rep. 2017;7(1):45637. doi:10.1038/srep45637

11. Olga A, Emmanouil M. Body-weight and psychological well-being in the UK general population. J Public Health. 2018;40(2):245-252. doi:10.1093/pubmed/fdx054

12. Huang C, Kogure M, Tomata Y, et al. Association of serum adiponectin levels and body mass index with worsening depressive symptoms in elderly individuals: a 10-year longitudinal study. Aging Ment Health. 2020;24(5):725-731. doi:10.1080/13607863.2019.1584877

13. Kivimaki M, Jokela M, Batty GD. Does obesity really protect against psychological distress? Examining the 'fat-jolly' versus 'fat-sad' hypotheses using mendelian randomization. J Intern Med. 2011;269 (5):519-520. doi:10.1111/j.1365-2796.2011.02357.x

14. Kim E, Song JH, Hwang JY, et al. Obesity and depressive symptoms in elderly Koreans: evidence for the "jolly fat" hypothesis from the Ansan Geriatric (AGE) study. Arch Gerontol Geriatr. 2010;51 (2):231-234. doi:10.1016/j.archger.2009.10.014

15. Yim G, Ahn Y, Cho J, et al. The "jolly fat" effect in middle-aged Korean women. $J$ Womens Health. 2017;26(11):1236-1243. doi:10.1089/jwh.2016.6254

16. Fk K, Cd E, R-gl O, et al. Urinary phthalate metabolite associations with biomarkers of inflammation and oxidative stress across pregnancy in Puerto Rico. Environ Sci Technol. 2014;48(12):7018-7025. doi:10.1021/es502076j

17. Dearborn PJ, Robbins MA, Elias MF. Challenging the "jolly fat" hypothesis among older adults: high body mass index predicts increases in depressive symptoms over a 5-year period. $J$ Health Psychol. 2018;23(1):48-58. doi:10.1177/1359105316675209

18. Zhao G, Ford ES, Dhingra S, Li C, Strine TW, Mokdad AH. Depression and anxiety among US adults: associations with body mass index. Int $J$ Obes. 2009;33(2):257-266. doi:10.1038/ ijo. 2008.268

19. Yue C, Ying J, Yang M. Association between obesity and depression in Canadians. $J$ Womens Health. 2009;18(10):1687-1692. doi:10.1089/jwh.2008.1175

20. Forman-Hoffman VL, Yankey JW, Hillis SL, Wallace RB, Wolinsky FD. Weight and depressive symptoms in older adults: direction of influence? J Gerontol B Psychol Sci Soc Sci. 2007;62 (1):S43-S51. doi:10.1093/geronb/62.1.S43

21. Ohayon MM, Hong SC. Prevalence of major depressive disorder in the general population of South Korea. J Psychiatr Res. 2006;40 (1):30-36. doi:10.1016/j.jpsychires.2005.02.003

22. Li S, Chen Y, He G. Laugh and grow fat: happiness affects body mass index among Urban Chinese adults. Soc Sci Med. 2018;208:55-63. doi:10.1016/j.socscimed.2018.05.008

23. Zhu Y, Wang Q, Pang G, et al. Association between body mass index and health-related quality of life: the "obesity paradox" in 21,218 adults of the Chinese general population. PLoS One. 2015;10(6): e0130613. doi:10.1371/journal.pone. 0130613

24. You H, Li XL, Jing KZ, et al. Association between body mass index and health-related quality of life among Chinese older adults-evidence from a community-based study. BMC Public Health. 2018;18(1):1174. doi:10.1186/s12889-018-6086-1

25. Wang R, Wu M-J, Ma X-Q, et al. Body mass index and health-related quality of life in adults: a population based study in five cities of China. Eur J Public Health. 2012;22(4):497-502. doi:10.1093/eur$\mathrm{pub} / \mathrm{ckr} 080$ 
26. Liu R, Wu SM, Hao YT, et al. The Chinese version of the world health organization quality of life instrument-older adults module (WHOQOL-OLD): psychometric evaluation. Health Qual Life Outcomes. 2013;11:156. doi:10.1186/1477-7525-11-156

27. Du WJ, Zhou JY, Liu JJ, et al. Social-demographic correlates of the mental health conditions among the Chinese elderly. Sustainability. 2019;11(24):13. doi:10.3390/su11247114

28. National Health Commission. PRC [homepage on the Internet]. Healthy China action (2019-2030); 2019. Available from: http://www.nhc.gov. cn/guihuaxxs/s3585u/201907/e9275fb95d5b4295be8308415d4cd1b2. shtml. Accessed December 26, 2020.

29. Wei L, Zhicheng L, Yitan H, et al. Age and gender specific association between obesity and depressive symptoms: a large-scale cross-sectional study. BMC Public Health. 2020;20(1):1565. doi:10.1186/s12889-020-09664-8

30. Kim J, Noh J-W, Park J, Kwon YD. Body mass index and depressive symptoms in older adults: a cross-lagged panel analysis. PLoS One. 2017;9(12):e114891. doi:10.1371/journal.pone.0114891

31. Geoffroy MC, Li L, Power C. Depressive symptoms and body mass index: co-morbidity and direction of association in a British birth cohort followed over 50 years. Psychol Med. 2014;44 (12):2641-2652. doi:10.1017/S0033291714000142

32. Xu Y, Zhou Z, Li Y, et al. Exploring the nonlinear relationship between body mass index and health-related quality of life among adults: a cross-sectional study in Shanxi Province, China. Health Qual Life Outcomes. 2015;13:153. doi:10.1186/s12955-015-0347-9

33. Zhang J, Xu L, Li J, et al. Gender differences in the association between body mass index and health-related quality of life among adults: across-sectional study in Shandong, China. BMC Public Health. 2019;19(1):1021. doi:10.1186/s12889-019-7351-7
34. Magallares A, Pais-Ribeiro JL. Mental health and obesity: a meta-analysis. Appl Res Qual Life. 2014;9(2):295-308. doi:10.1007/ s11482-013-9226-x

35. Zhang L, Liu K, Li H, et al. Relationship between body mass index and depressive symptoms: the "fat and jolly" hypothesis for the middle-aged and elderly in China. BMC Public Health. 2016;16 (1):1201. doi:10.1186/s12889-016-3864-5

36. Koksal UI, Erturk Z, Koksal AR, Ozsenel EB, Kaptanogullari OH. What is the importance of body composition in obesity-related depression? Eurasian J Med. 2017;49(2):102-106. doi:10.5152/ eurasianjmed.2017.16129

37. Kortt MA, Dollery B. Association between body mass index and health-related quality of life among an Australian sample. Clin Ther. 2011;33(10):1466-1474. doi:10.1016/j.clinthera.2011.08.009

38. Gorber SC, Tremblay M, Moher D, Gorber B. Diagnostic in obesity comorbidities - a comparison of direct vs. self-report measures for assessing height, weight and body mass index: a systematic review. Obes Rev. 2007;8(4):307-326. doi:10.1111/j.1467-789X.2007.00347.x

39. Dekkers JC, MFv W, Hendriksen IJ, Twisk JW, Mechelen W. Accuracy of self-reported body weight, height and waist circumference in a Dutch overweight working population. BMC Med Res Methodol. 2008;8(1):69. doi:10.1186/1471-2288-8-69

40. Romero-Corral A, Somers VK, Sierra-Johnson J, et al. Accuracy of body mass index in diagnosing obesity in the adult general population. Int J Obes. 2008;32(6):959-966. doi:10.1038/ijo.2008.11
Risk Management and Healthcare Policy

\section{Publish your work in this journal}

Risk Management and Healthcare Policy is an international, peerreviewed, open access journal focusing on all aspects of public health, policy, and preventative measures to promote good health and improve morbidity and mortality in the population. The journal welcomes submitted papers covering original research, basic science, clinical \& epidemiological studies, reviews and evaluations, guidelines, expert opinion and commentary, case reports and extended reports. The manuscript management system is completely online and includes a very quick and fair peer-review system, which is all easy to use. Visit http://www.dovepress.com/testimonials.php to read real quotes from published authors. 